\section{Risco, incerteza e as possibilidades de ação na saúde ambiental*}

\section{Risk, uncertainty and the possibilities of action in environmental health}

\section{Renato Rocha Lieber}

Faculdade de Engenharia de Guaratinguetá

Universidade Estadual Paulista UNESP

Caixa Postal 205

12516-410 Guaratinguetá SP

lieber@feg.unesp.br

\section{Nicolina Silvana Romano-Lieber}

Faculdade de Saúde Pública

Universidade de São Paulo

Av. Dr. Arnaldo, 715

01246-904 São Paulo SP

nicolina@usp.br

\section{Resumo}

O conceito de risco vem tendo uso crescente no entendimento das relações entre saúde e ambiente. Uma revisão recente do seu emprego ${ }^{1}$ mostrou que o risco é próprio da condição humana e que a exclusão da incerteza promove a manutenção do status quo. O problema que se coloca é como propor ações de melhoria na saúde ambiental sob os pressupostos da dúvida e da incerteza que caracterizam a condição de risco. Como proposta de solução, a obra de H. Arendt ${ }^{2}$ prestou-se ao exame dos significados e das implicações da incerteza no campo do pensamento e no campo da ação. Os resultados mostram que o risco se insere na lacuna construída entre o passado e o futuro. Quando esta lacuna passa a ser entendida como espaço de possibilidades, a incerteza, produzida no campo do pensamento fomenta a liberdade e a participação no campo da ação. A valorização da subjetividade e o exercício do juízo promovem a configuração de novos contextos e de novas possibilidades de ação, tanto em relação à natureza como em relação aos homens. Este conhecimento novo se insere na lacuna entre passado e futuro e realimenta o processo. Conclui-se que as ações de "promoção da saúde" devem estar aptas a aceitar resultados não necessariamente idealizados. Na ação livre não existem certezas e a sua relevância não está nos fins que se possa estabelecer, mas no processo do seu exercício.

Palavras-chave: Política. Promoção da saúde. Auto-ação. Autoridade. Liberdade. Juízo.

\footnotetext{
* Este artigo contou com o estímulo e com a contribuição dos debates promovido entre os membros do GT "Saúde e Ambiente" da Associação Brasileira de Pós-Graduação em Saúde Coletiva (ABRASCO). A responsabilidade pelo produto final cabe expressa e exclusivamente aos autores.
} 
Abstract

The concept of risk has been increasingly used in the understanding of the relationship between health and environment. A recent review of its use ${ }^{1}$ showed that risk belongs to the human condition and that excluding uncertainty promotes maintaining the status quo. The question is how to propose actions to improve environmental health under the assumptions of doubt and uncertainty that characterize the condition of risk. As a proposal for a solution, the work of $\mathrm{H}$. Arendt ${ }^{2}$ examined the meanings and implications of uncertainty in the field of thought and in the field of action. The results show that risk lies in the gap between the past and the future. When this gap is understood as a space for possibilities, uncertainty, produced in the field of thought, fosters freedom and participation in the field of action. Valuing subjectivity and exercising judgment promote configuring new contexts and new possibilities for action, both in relation to nature and in relation to human beings. This new knowledge inserts itself in the existing gap between past and future and feeds the process again. One can conclude that "heath promotion" actions must be apt to accept results that are not necessarily idealized. There is no certainty in free action and its relevance is not in the ends one can establish, but rather in the process of its exercise.

Key Words: Politics. Health promotion. Selfaction. Authority. Freedom. Judgment.

\section{Introdução}

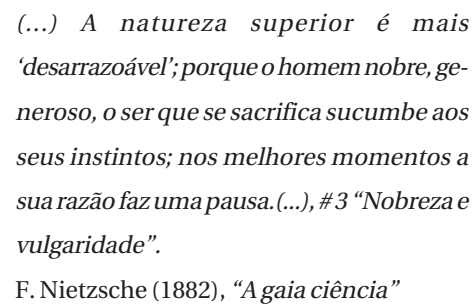

As relações entre saúdee ambientevêm sendo estudadas e geridas sob numerosas denominações. Ainda que sob ênfases próprias e distintas, cada uma delas vêm também compartilhando de um pressuposto mais geral, assumindo-se, em quase todas, que as condições do ambiente influenciam a forma da expressão da vida e que o viver altera o ambiente em diferentes aspectos. A questão terminológica foi objeto de estudo recente por Ordonez ${ }^{3}$. Este, confrontando expressões e conceitos usados nas declarações supranacionais, propôs o termo "saúde ambiental", onde a condição de "ambiente" ou de "meio ambiente" não estaria limitada aos aspectos sólidos, líquidos e gasosos deste, mas incluiria também a totalidade do mundo físico que rodeia o homem, inclusive os outros homens e suas inter-relações. Tal entendimento, aceito no presente trabalho, converge também com as ponderações já formuladas por Tambellini e Câmara ${ }^{4}$, onde a saúde ambiental se insere na saúde coletiva ao abarcar as relações ditas de "produção/saúde/ambiente".

As relações entre saúde e ambiente, doravante de saúde ambiental, estão inevitavelmente associadas às relações de risco. Isto porque o "risco", enquanto idéia subjacente de "mensuração de algo não totalmente estabelecido", vem se mostrando a forma mais adequada para se apresentar conhecimento científico relativo a um objeto por demais complexo, como o ambiente. Este, ainda que refratário às reduções usuais da ciência, como se impõe na experimentação, pôde se apresentar em termos quantificáveis e verificáveis. Para tanto, o ambiente foi fragmentado em "fatores" e a caracterização de relações probabilísticas entre fa- 
tores do ambiente e a condição de saúde converteu os primeiros, de maneira precisa e inequívoca, em "fatores de risco". Tal rigor, contudo, ofusca a inexatidão, ou imperfeição, própria e necessária a toda relação de risco (sempre uma possibilidade em si). Na busca do entendimento das coisas da natureza, há não somente uma lacuna entre o que "é" e o que "se pode medir", mas também outra lacuna entre o que "foi" e o "vir a ser", particularmente quando a idéia de risco é usada para prognósticos.

A condição de "possibilidade", própria do risco, já seria suficiente para se justificar a incerteza como necessária. Mesmo assim, muitos prognósticos vêm sendo formulados e aceitos, como se as possibilidades pudessem se conduzir por determinações desconhecidas. Como resultado, "fator de risco" converte-se em "causa”, graças ao pressuposto de uma lei natural subjacente e oculta, lembrando em parte o percurso heurístico da bacteriologia clássica. O paradoxo evidente não está no processo de escolha induzida de algumas variáveis (em detrimento de outras), convertidas em "fatores" para se medir freqüências. O absurdo é conjeturar que um fenômeno que se apresenta por um sem número de condições aleatórias, ou contingentes, possa ele mesmo ser resultante de uma condição causal não transcendental. É condição ao risco, portanto, o pressuposto do acaso. E, na condição de uso do risco como prognóstico, é recurso indispensável a configuração simultânea do passado e do futuro, artifício mental alcançado ao se perceber a realidade enquanto um sistema, conforme Luhmann ${ }^{5}$ Logo, a incerteza se impõe na idéia de risco como uma decorrência, tanto da ignorância que se tem do mundo como da ignorância de cada um sobre si mesmo.

Muito embora a ação humana possa estar constrangida pela incerteza relativa às coisas do mundo ou da consciência, não é certamente a incerteza que cerceia o curso do agir. Seja na relação do homem com a natureza, seja na relação do homem com outros homens, o agir é condição necessária e, sob a incerteza, a sua forma quase sempre mais freqüente. De modo paradoxal, a condição de risco impõe uma ação, justamente pela incerteza inseparável. Revisão recente do conceito de risco ${ }^{1}$ mostra que o pensamento econômico contemporâneo, por exemplo, não pôde se completar sem pressupor a convergência da ação, do risco, da incerteza e da racionalidade extrapolada. Mas o mesmo trabalho também mostra que o uso do conceito de risco vincula-se ao exercício do poder, que é, em última análise, a condição de promoção ou de inibição da ação, ainda que não possa de fato suprimila. Conforme o modelo proposto pelos autores, risco, incerteza, ação e conhecimento são aspectos inevitavelmente ligados à condição humana na sua relação com o mundo. Neste arranjo particular, o homem se vê na situação contraditória de um ser natural contra a natureza e, ao mesmo tempo, de um ser sujeito ao risco pela sua necessidade de superar a ignorância, ao preferir o curso racional da descoberta e do conhecimento. Ocorre que, ao se converter este conhecimento e seus produtos em mercadorias, próprias à acumulação do capital, há um tal dinamismo retroalimentado que essas contradições são distendidas ao limiar da ruptura. Nunca antes houve tanta racionalidade nas ações humanas relativas à natureza e, ao mesmo tempo, nunca antes se temeu tanto por ela.

Mas se este é o contexto necessário, com que base pode-se propor ações de melhoria na saúde ambiental? Com que base pode-se adotar as recomendações supranacionais pró-ativas de "Promoção de Saúde", como aquelas firmadas e reiteradas em diferentes oportunidades resumidas na carta de Otawa de $1986^{6}$ ? Em outras palavras, o problema que se coloca é: Como agir e fomentar a ação em prol de uma melhor relação entre saúde e ambiente sob os pressupostos da dúvida $\mathrm{e}$ da incerteza, como é próprio da relação de risco?

\section{Objetivos e métodos}

Como objetivo geral, este trabalho se propõe a estabelecer as implicações da formalização conceitual do risco na concep- 
ção de políticas no âmbito da saúde ambiental. Em termos específicos, pretende-se;

- explorar o significado de incerteza, própria da condição do risco;

- traduzir o significado estabelecido para o campo da ação;

- mostrar que a preservação da incerteza, como aquela proporcionada pelo conceito de risco, é a forma de garantir a eqüidade, a participação e o espaço da expressão da subjetividade e da descoberta.

Para tanto, apresenta-se uma investigação no âmbito da teoria política, tomando como referência a obra de Hannah Arendt,

"Betwenn Pass and Future"

H. Arendt, acompanhando a tradição filosófica da fenomenologia de Heidegger (1889-1976) e o existencialismo de Jaspers (1883-1969), foi detentora de um pensamento próprio e original. Refugiada nos EUA, contribui com várias obras de filosofia política que analisam a forma totalitária de poder. Por vezes polêmica, foi também alvo de críticas daqueles que não podiam conceber que o mal pudesse ser também decorrente da ação do homem comum, alienado e desumanizado no exercício burocrata e metódico. Do conjunto de sua obra destaca-se a promoção do entendimento da ação que, para ela, só podia ser concebida dentro da esfera pública, onde a liberdade pode se realizar?

A obra aqui tomada para estudo foi uma coletânea de 6 ensaios, em que diferentes temas se articulam em torno do significado da ação. Seu propósito foi deslindar conceitos na linguagem política envolvida em assuntos aparentemente díspares como história, autoridade, liberdade, educação, cultura e verdade. Sua proposta foi promover um "exercício" para se adquirir "experiência em como pensar", colocando-se em "suspenso o problema da verdade", conforme Arendt (op. cit. p. 41). Deste conteúdo, propõe-se aclarar com outras luzes o significado da incerteza e da ação no contexto da condição de risco, sendo esta entendida sob um enfoque ampliado, conforme proposição de Lieber \& Romano-Lieber ${ }^{1}$.
A exposição está dividida em 3 partes. Na primeira, apresenta-se a condição de risco dentro do campo do pensamento, aprofundando-se o significado da incerteza dela decorrente. Na segunda parte, desenvolve-se as particularidades presentes no campo da ação, com destaque para os significados de ação, autoridade, liberdade e juízo. Na terceira e última parte, discute-se a articulação destes dois campos, onde a incerteza constitui a interface, e confronta-se este entendimento com as propostas oficiais de "Promoção de Saúde", enquanto ação política para melhoria da saúde ambiental.

\section{O campo do pensamento: gênese da (in)certeza}

$\mathrm{O}$ ato de pensar capacita o homem à reflexão sobre si e sobre o mundo. Assim fazendo, ele assume uma posição de não indiferença, obrigando-se a buscar um sentido nas coisas. Graças à possibilidade de sentido, o mundo torna-se cognoscível e a ação pode, assim, ser conduzida como que "guiada pela razão”. É desta forma que se orientam, embora fazendo uso de diferentes recursos, tanto as concepções científicas como as não científicas. Em cada caso, busca-se entender o mundo como um sistema; em cada caso busca-se a "conexão" capaz de fazer o passado dar as respostas para as indagações relativas ao futuro. Acontecimentos aparentemente desconexos sempre foram objetos de exame, confronto e ajuste com um quadro de referência pré-estabelecido. Coube à ciência moderna, não a refutação dessa busca de "conexão", algo que a biologia contemporânea mostra nas pesquisas genéticas, mas sim a promoção de dúvidas relativas ao "quadro de referência preestabelecido".

Esta nova forma de olhar, ou o "pensamento moderno”, não excluiu necessariamente a forma anterior do pensar, que sempre resiste, como mostram os paradigmas de Kuhn' ${ }^{8}$. Contudo, suas conseqüências modificaram sobremaneira o campo da ação, que passa não mais a ser constrangido pelo que foi, mas subitamente vislumbra jus- 
tificar-se no vir a ser (como nos resultados dos experimentos). Entre as várias implicações da modernidade, Arendt ${ }^{2}$ destaca, por exemplo, o surgimento da confusão entre sentido e fim com o marxismo, como se o sentido da vida do carpinteiro fosse de antemão a mesa que ele alcança ao fim da sua ação (p. 113). Ao mesmo tempo, a autora mostra que a condição moderna de confutação do passado não foi um procedimento abrupto, mas sim o resultado de um longo processo na forma de pensar ocidental, particularmente na sua maneira de entender o tempo e, portanto, de perceber a história. Como o risco pode ser entendido como um recurso de ligação do passado com o futuro, convém examinar com detalhes como a incerteza se constrói no campo do pensamento a partir do entendimento da história.

Ao contrário do pensamento cristão, o pensamento grego antigo entendia os homens como mortais, em distinção da natureza como imortal, já que os homens podiam ser entendidos como indivíduos presentes num mundo imutável em eterna repetição. A vida humana adquire a individualidade ao romper esta ordem cíclica, por exemplo no ato "não natural" do velejar. É uma relação particular com a natureza que se caracteriza, pois a forma de existência humana violenta a natureza em sua eterna quietude (p. 71). E a história, enquanto relato destes feitos exemplares, se faz pela ação do homem. Todavia, para Arendt, o ponto decisivo na moderna concepção de história não foi a noção de mortalidade grega nem aquela de imortalidade extraterrena cristã, mas sim a possibilidade de se contar o tempo tomando o nascimento de Cristo como uma inflexão (p. 100). Quando o mundo ocidental no século XVIII passou a se referir aos acontecimentos históricos como antes e depois de Cristo, o tempo passou também a se estender infinitamente para trás e para frente, configurando à humanidade uma potencial imortalidade terrena (p. 101). Nesta nova forma de tempo infinito, não apenas a noção de um fim é virtualmente inconcebível (p. 109), mas as permanências de eternidade passam a ser decorrentes da fluidez de um processo, e não mais da estabilidade das estruturas (p. 110).

A questão seguinte é, portanto, entender a natureza desse processo fluido que liga o passado e o futuro, capaz de garantir simultaneamente a sua infinitude e as rupturas na ordem cíclica; um processo que ocorre no âmbito do pensamento, em busca de sentido e sem estar preso à doação de finalidades. Arendt apresenta uma proposta de interpretação inspirada numa parábola de F. Kafka (1883-1924), analisando o significado do presente na condição humana, entendido como a lacuna entre o seu passado e o seu futuro. O presente pode ser entendido como o lugar do embate entre duas forças: as forças do passado, que pressionam o homem para a frente; e as forças do futuro, que, em sentido contrário, o forçam para trás, bloqueando o seu caminho para diante. Nesta lacuna há mais de uma luta, pois não só o passado luta contra o futuro, mas o homem também luta contra ambos em defesa do seu território (p. 33). Do ponto de vista do pensamento no homem, o tempo não é mais um continuum, mas é uma seção, ou um talho, capaz de estabelecer onde ele está. Tal seção não configura o presente que usualmente se entende, mas sim o espaço da "sua" luta contra as forças do passado e as forças do futuro (ou o "seu" território). É na medida em que a luta se estabelece que se torna possível a distinção entre passado, presente e futuro (p. 37). Em outras palavras, é a ação no presente que promove a ruptura no tempo e o fazer da história. Forças do passado forçam o sujeito a seguir para a frente, quer numa continuidade do que sempre foi, quer numa mudança ditada pela experiência. Ao mesmo tempo, agem as forças do futuro, bloqueando a sua passagem, tanto com as possibilidades como com as impossibilidades do novo desconhecido. Passado e futuro lutam entre si e o homem luta com ambos ao expressar desejo.

Na parábola de Kafka, o personagem sonha, em algum momento, se colocar acima do campo de antagonismo, alçado à posição de juiz por sua experiência de luta. Este momento, que para Kafka é uma noite de trevas 
absoluta, Arendt interpreta como o instante da modernidade em que as tradições (ou o "quadro de referências") já não mais orientam. É a noite de trevas, pois nada mais sustenta o sujeito a não ser o seu próprio juízo. Além disso, ela percebe que as forças do passado, cuja origem se encontra no infinito pregresso, não se alinham necessariamente com as forças vindas do infinito futuro. Em sentidos opostos e em diferentes direções, estas forças podem estabelecer um vetor resultante (Figura 1). Para ela, este vetor, cuja origem está no presente sob os momentos de luta e ruma para o infinito, representa as possibilidades do pensamento, capaz de expressar aquele juízo.

Em síntese, a concepção moderna de mundo, rejeitando a tirania da reprodução da tradição, não excluiu a dúvida nem a introduziu, mas apenas mudou a forma de se lidar com ela. A incerteza, que sempre fez parte do contexto da decisão, tomou relevo inaudito quando o presente, enquanto lugar de ação, passa a ser lugar não apenas do de- sejo, mas também da reflexão. Se por um lado é o desejo que promove a rejeição e a aceitação de riscos, na condição moderna é o pensamento, com suas infinitas possibilidades, que estabelece o juízo, antes excluído pela tradição. Obrigando-se a conviver com a incerteza, a ação do homem moderno não pode prescindir de um pensamento particular, onde o sentido das coisas e do mundo não é dado mais de antemão, mas deve ser descoberto por ele mesmo.

Além disso, enquanto a lógica depende essencialmente do eu racional, o juízo depende dos outros. Pois julgar é a capacidade de ver não apenas a partir do próprio ponto de vista, mas a partir da perspectivas de todos (Arendt, p. 275). Ao juízo, portanto, não basta o campo do pensamento, embora este seja necessário; ele requer também a interação entre os homens, própria do campo da ação. Quanto mais pessoas estiverem presentes na mente de quem julga ao ponderar um dado problema, mais válida é a sua opinião (p. 299).

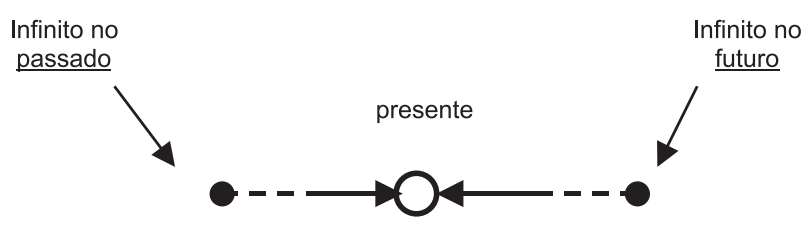

(a) tempo linear

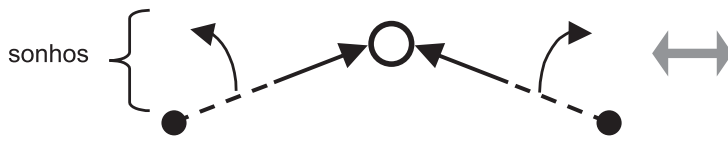

(b) linearidade violada
Possibilidade atividade do pensamento

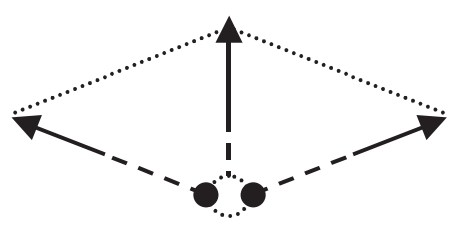

(c) o presente como lacuna

Figura 1 - Metáfora da condição humana e o curso do tempo. (a) Passado e futuro são forças que se opoem no presente, conf. F. Kafka. (b); o homem rompe a linearidade do tempo, elevando-se através dos sonhos; (c) o resultado é o presente como uma lacuna, determinada pela possibilidade infinita da atividade do pensamento. Adaptado da interpretação de Arendt (1961).

Figure 1 - Metaphor of the human condition and the course of time. (a) Past and future are forces that oppose each other in the present, see F. Kafka. (b); peolple break the linearity of time, elevating themselves through dreams; (c) the result is present as a gap, determined by the infinite possibility provided by thinking. Adapted from Arendt's interpretation (1961). 


\section{O campo da ação: experiências da (in)certeza}

O campo da ação não se confunde com o campo do pensamento, ainda que a condição necessária nos pressupostos da razão os mantenha ligados. Nele destaca-se o agir, que não pode ser confundido com o fabricar. Segundo Arendt (p. 91), enquanto a fabricação tem um início e um fim, a ação pode ser entendida em si e por si como absolutamente fútil, dada a imprevisibilidade dos resultados que uma cadeia de acontecimentos estabelece e que não se pode prever de antemão. $\mathrm{O}$ fato de se poder direcionar a ação de alguma forma, ou de se poder explicar seu resultado a posteriori (atividade do pensamento), não implica em domínio ou previsibilidade do processo em curso ${ }^{2}$.

O agir é o movimento, ou a continuação de algo histórico (Arendt, p. 214). O campo da ação, portanto, não está no passado (com sua condição fatual), nem no presente (enquanto resultado do passado), mas está no futuro, aberto às suas possibilidades (p. 319). A ação humana, enquanto a ação livre, distingue-se exatamente por esta capacidade de começar algo novo. E é a faculdade de liberdade, ou "pura capacidade de começar", que permite ao campo da ação dar à realidade esse caráter de "improbabilidade infinita”, como se o impossível acontecesse por "milagre". Isto porque é a ação humana que rompe o automatismo em que se encontra a natureza e a história, um automatismo voltado sempre para a ruína de todo ser que se encaminha para o não-ser (p. 214), como explica o aumento da entropia proposto pela termodinâmica. Esta reserva de potência, própria a todo ser humano, faz dele um ser para a ação (p. 95). Todavia, quando o passado e o presente são tomados enquanto partes resolutivas do futuro, a condição humana priva-se desta potencialidade (p. 319).

Por conseguinte, além do agir, propriamente dito, é condição precípua ao campo da ação também uma potencialidade de ruptura que lhe é inerente. Tal potencialidade, contudo, sujeita-se a diferentes constrangimentos. Estes constrangimentos, expressos na forma de configuração do futuro, são analisados pela autora como produtos da lógica pragmática e da expressão da autoridade, contrários à efetivação da liberdade e do juízo.

\section{Lógica pragmática}

No pragmatismo, a ação humana é concebida à imagem do fazer. Como o fazer tem um começo e um fim, o sentido da ação passa a ser confundido com o seu propósito, ignorando-se que o sentido só surge quando a ação chega a seu fim, e não antes dele. Esta configuração de fim, evidentemente, exclui a condição de infinitude da história e impõe à realidade um significado sujeito puramente às leis preconcebidas pelo homem. $\mathrm{O}$ ato, que ao se iniciar altera a realidade e a torna mais imprevisível, perde a sua imprevisibilidade. Tal ocorre quando um processo universal de causas dá a todo incidente particular um dado sentido de ordem e necessidade, sentido este que, buscado no passado, tem tanto sentido quanto quaisquer outros que se lhe possa dar (Arendt, p. 11325).

\section{Expressão da autoridade}

A autoridade não se confunde com o poder, pois a sua fonte transcende o poder. Arendt (p. 127-87) localiza a origem da noção de autoridade na forma política romana e, não sem razão, confere ao exercício papal o arquétipo da autoridade. Os romanos entendiam o crescimento para o passado e não para o futuro. A glória decorria de um agir conforme o consagrado pelo modelo, e o passado se santificava graças à tradição preservada. Desse entendimento romano surge a condição do perito, aquele cuja solidez moral e de conhecimento detém a capacidade de aumentar o já instituído no passado. A autoridade, portanto, como o senado romano, pressupunha o uso da tradição para lastrear o que ia ser feito, e não para prognosticar o resultado futuro.

$\mathrm{O}$ argumento central no pensamento autoritário é relacionar tudo a um contexto 
funcional (Arendt, p. 140). A sua exeqüibilidade decorre do uso deste conceito romano, expandido à condição de perito e acrescido da lógica platônica, capaz de conceber a possibilidade da idéia enquanto norma. Todavia, a expressão autoritária acabou convertendo-se em formas de violência. Aquilo que sempre havia sido o recurso de convencimento político (ação entre os homens pela palavra) passa a ser usado num âmbito onde a ação e o fazer se confundem, reino absoluto das finalidades. Como resultado, "vida saudável" torna-se um produto de "dietas", formalizadas objetivamente por uma relação de "peso/altura", enquanto a cidadania passa a ser "compromisso conservacionista", atestado pela lata amassada e cedida ao catador miserável.

\section{Liberdade}

A cultura ocidental sempre teve um claro conceito de liberdade até o advento do cristianismo. Em toda história greco-romana, liberdade sempre significou ser "livre da necessidade" ou "de outros homens", uma condição própria, portanto, dos donos de escravos. O progresso da fé cristã converteu essa condição dos corpos a uma condição do espirito, e a liberdade passou a ser entendida como "liberdade para a boa via", ou a "dominação da necessidade” (Arendt, p. 159). Consolidou-se um entendimento de que os homens são livres e se orientam pela causalidade. Na causação, há a força proporcionada pela natureza e os motivos estabelecidos pela conduta humana. Assim, o ato, pressupostamente livre, sujeita-se ao mesmo tempo aos princípios causais do mundo e à motivação interna de cada um (p. 188).

Estas transformações circunstanciais fizeram com que o entendimento de liberdade fosse transferido do âmbito da política (relação entre os sujeitos) para o âmbito interno de cada um (do sujeito consigo mesmo) ou da vontade. Todavia, a liberdade vincula-se não só à ação, mas também à sua expressão, pois a razão da política é a liberdade, e o domínio da experiência livre é a ação. O sujeito que "sente", mas não pode expressar este sentimento no âmbito externo, não detém liberdade enquanto política (Arendt, p. 192). A liberdade, portanto, na medida de um fenômeno político, não se confunde com livre-arbítrio (capacidade de escolha entre o bom e o mau). A liberdade não é um fenômeno da vontade, mas passou a ser assim entendida quando de problema político converteu-se em problema filosófico, decorrente do paradoxo constituído pela incapacidade da vontade de dominar o próprio eu (p. 204).

Diante destas considerações, a autora conceitua liberdade como uma propriedade da ação livre, aquela ação em que há " $l i$ berdade para chamar à existência o que antes não existia" (p. 198). A ação livre é tanto livre de motivos como livre do fim intencionado, enquanto um efeito previsível. Isto não significa uma ação destituída de motivos e objetivos, mas sim que estes, enquanto fatores determinantes, capacitam a ação a transcendê-los. A ação livre, enquanto forma de preservação do modo de ser, não pode ser ditada por um certo ou errado dado de antemão (tolhendo a liberdade), guiada pelo intelecto ou sob ordens da vontade. A ação livre brota de algo inteiramente diverso, brota daquilo que ela chama de um "princípio inspirador", cuja ciência só se dá na plenitude do ato.

Para Arendt ${ }^{2}$, o "princípio inspirador", ao contrário da vontade que se esgota e do juízo que se altera, não se exaure, não perde vigor ou validade, e detém permanência mesmo após a conclusão da ação. Os "princípios" são aquilo que se entende por virtude ou distinção. Os princípios compreendem a excelência (honra, glória e amor à igualdade), mas também subentendem o medo, a desconfiança e o ódio. A liberdade surge quando estes princípios são atualizados pelo agir, e a virtuosidade está na arte da realização (o desempenho) e não no produto final, sujeito às circunstâncias.

\section{Discussão}

As idéias aqui expostas impõem a necessidade de se formalizar entendimentos onde 
os sentidos não se confundem com os fins, onde as ações no âmbito da natureza não se confundem com aquelas concebidas no âmbito dos homens. É a partir desta distinção que os conceitos em uso relativos a risco, ambiente, incerteza e ação, oferecem novas facetas à discussão.

\section{O âmbito da natureza}

O entendimento do risco, conceituado por Lieber \& Romano-Lieber ${ }^{1}$ e exposto na introdução, pode ser deduzido como decorrente de um modelo de ação relativo à natureza. Sendo uma abordagem parcial da possibilidade da ação, ao excluir aquela relativa aos homens entre si, o seu referencial restringe-se ao "fazer". Na sua coerência, a condição de risco se expressa no reino da violência. Tal aspecto não exclui, mas circunscreve, as propriedades que foram destacadas naquele modelo, permitindo mostrar o risco como uma função geradora para:

- promoção do "círculo virtuoso" da acumulação capitalista nas regras de mercado, cujo resultado é o aumento da riqueza e da disponibilidade inaudita de supérfluos e, por conseguinte, de bemestar;

- conhecimento novo, passível da apropriação capitalista, capaz, por exemplo, de prolongar as possibilidades de vida;

- viabilização do sistema de mercado nas crises geradas por suas próprias regras (busca da maximização de lucros e da minimização de custos).

É também neste referencial do "fazer", de fins justificando os meios, que a teoria econômica alcança a sua lógica. Como demonstrou Pareto 9 , se o objetivo é proporcionar o maior bem-estar à sociedade, através da riqueza, os preços estabelecidos na condição de mercado perfeito determinam as condições ótimas para o nível de produção e de consumo, ou o "ótimo paretiano". A busca deste "ótimo", via a maximização de lucros e a minimização de custos é o propósito não só da eficiência produtiva, mas também do consumidor que busca dar a melhor condição de compra em relação ao seu orçamento. Todavia, a maximização da condição de eficiência (todos ganham o máximo possível, configurando a condição ótima) não coloca a pergunta "quem está perdendo”, já que todos ganham. Tal é possível, porque as naturezas biota e abiota, incluindo entre os primeiros a fração biológica do homem, não fazem relações de troca no mercado, pois se prestam apenas como meios de produção. Assim, tanto os consumidores (comprando mais barato) como os produtores (vendendo sob o menor custo) maximizam, graças não apenas ao risco, que articula o modo capitalista de produção, mas também graças tanto à degradação das condições de trabalho como a da natureza. Não surpreende, portanto, a falta de congruência da prática com o "discurso ecológico", tanto entre produtore ${ }^{10}$ como entre consumidores $^{11}$.

A condição de ambiente que daí se estabelece, tanto laboral como extra-laboral, é sobrepujada pela lógica da otimização nas relações de mercado. Tal acontece porque $o$ sujeito, ainda que degradado "biologicamente" pelo processo de maximização, passa também a ter acesso aos produtos obtidos pela degradação de que ele próprio foi vítima. E, pela lógica do "mercado perfeito", o preço não se estabelece por critério diferente da maximização em relações de custo/ benefício, mas pelas relações de oferta e procura, bem como pelo fim preestabelecido (a maximização daquelas). Torna-se inconcebível, nesta racionalidade, o senso comum "minha vida não tem um preço".

Não é sem razão, portanto, que o mercado freqüentemente seja objeto de intervenção pela ação social, na forma de leis, regulamentos e normas que deveriam, por princípio, constranger e restringir a sua plena otimização. Isto implica necessariamente em maiores custos e redução de acesso ao consumo, até que alguém se "exponha ao risco" de algo novo, ainda não imaginado, e, portanto, ainda não constrangido (a inovação de Schumpeter ${ }^{12}$ ). Ora, esta fase intermediária constitui um outro campo de ação, aquele da "relação entre os homens", onde a lógica da otimização e do pragmatismo, pró- 
pria do fazer, não procede. Neste contexto, necessariamente político, pode ou não haver liberdade. E a liberdade decorre em parte da palavra não autoritária, conforme proposto por Arendt ${ }^{2}$, ou seja, possível graças à incerteza gerada no campo do pensamento (Figura 2). Entende-se assim, porque as principais economias centrais, envolvidas numa crise econômica prolongada (EUA e Japão), resistem aos argumentos da proteção ambiental global, que vêm sendo enfatizados justamente sob os termos da incerteza, como as relações de clima.

Quando a incerteza alcança o campo da ação, propiciando que a subjetividade se expresse, as percepções do mundo se modificam (Figura 2). Com isso, ampliam-se as possibilidades do conhecimento e criam-se formas de ação antes não cogitadas pela ausência daquelas perspectivas novas. Ainda que a perspectiva colocada não seja ela mesma fruto de um procedimento racionalista, ela propicia um novo espaço para reflexão, capaz de formular novas inferências causais e de ampliar o contexto do acontecimento que a causa deflagra, no vaivém entre causa e contexto ${ }^{13}$.

Ao mesmo tempo, a força da expressão subjetiva deflagra possibilidades de compartilhamento. Mas, conforme Adorno ${ }^{14}$ (p. 60), aquilo que é objetivo decorre exatamente daquilo que não se questiona, ou seja, daquilo que é subjetivamente compartilhado por todos. Desse modo, o contexto, objeto da ação, torna-se passível de uma nova ponderação dos seus diferentes fatores (fatores de risco). Fruto do consenso ou juízo, esta ponderação é única, pois é circunstancial no tempo e própria daqueles sujeitos compartilhantes. O resultado é tanto uma nova pos-

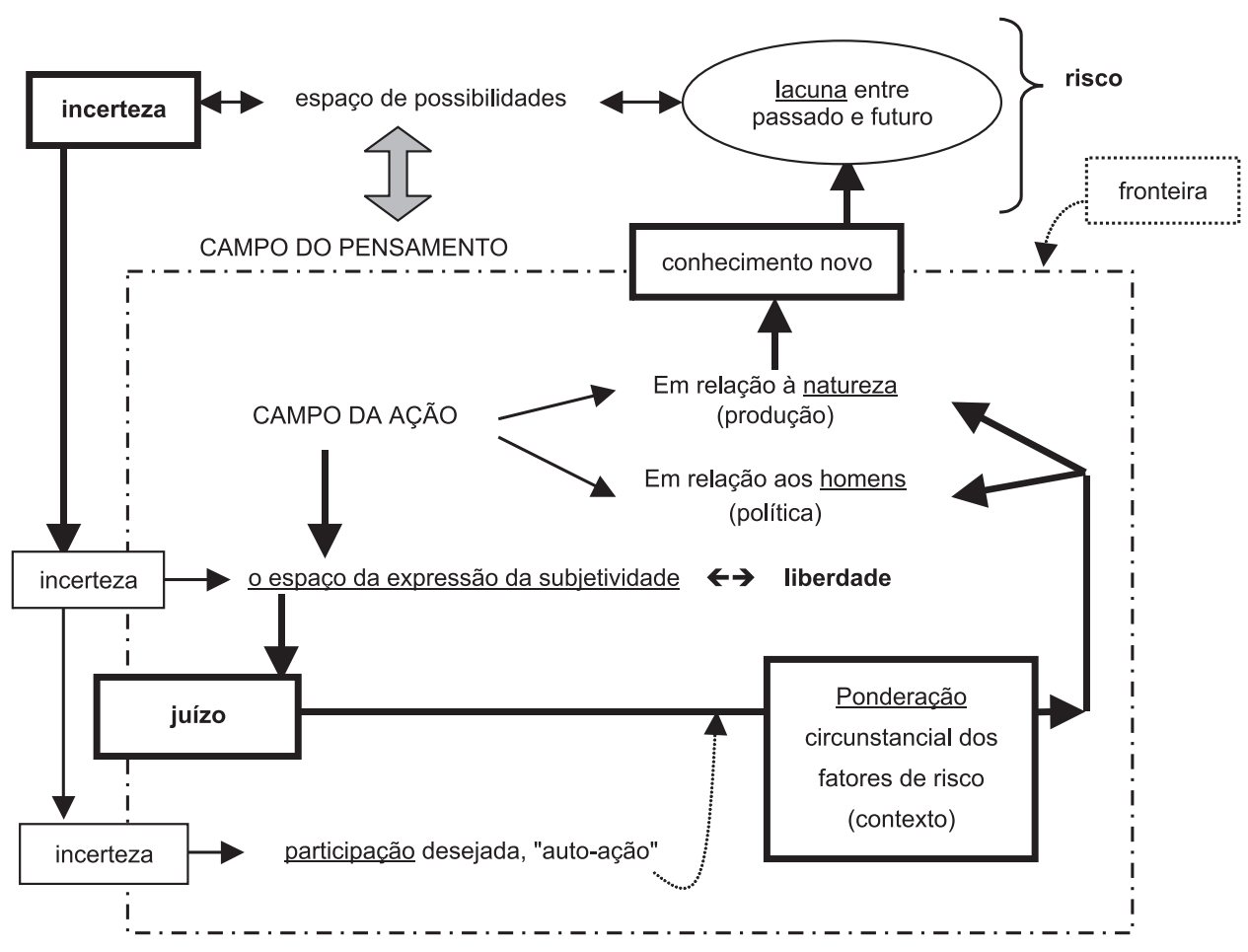

Figura 2 - Implicações do significado da incerteza (campo do pensamento) no campo da ação. A linha em negrito corresponde ao processo promovido pela incerteza no contexto da ação sob risco. O resultado é um "circulo virtuoso" cujo produto é o conhecimento novo. Figure 2 - Implications of the meaning of uncertainty (field of thought) in the field of action. The dark line corresponds to the process promoted by uncertainty in the context of action under risk. The result is a "virtuous circle" whose product is new knowledge. 
sibilidade de formular a ação, quer em relação à natureza, quer em relação aos outros homens, como a geração de um novo conhecimento pela experiência nova, cujo significado em si foi um "risco". Ora, é esse mesmo conhecimento novo que abre uma fenda na continuidade entre o passado e o futuro, e que, paradoxalmente, vai trazer mais incerteza. Porquanto se a experiência nova o possibilitou, outros ainda mais serão possíveis, graças ao fluxo incessante de incerteza entre o campo de pensamento e o campo da ação.

\section{O âmbito dos homens}

A garantia do fluxo da incerteza do campo do pensamento para o campo da ação se dá pela expressão da liberdade. Mas esta se expressa no espaço público, o campo da ação entre os homens, onde prevalece a política e suas diferentes formas de convencimento. Todavia, o que se observa na saúde ambiental é o discurso político que, fazendo uso da incerteza, não é capaz de colocar em dúvida suas próprias convicções. Esta forma de ação, própria de uma relação voltada para os fins, se expressa pela condição de autoridade, calcada, como visto, na tradição ou na perícia. O âmbito político converte-se no âmbito do fazer, próprio da ação pragmática e da violência.

A tradição confunde-se com o pragmatismo, pois é sempre mais fácil fazer da forma conhecida, própria de limitações e possibilidades avaliadas de antemão. Por isso, toda visão autoritária é também pragmática. A ação escolhida, conduzida e implementada numa estrutura previamente dada e intolerante é, na maior parte das vezes rápida, certeira e defensável, pois se justifica exatamente por ser rápida, certeira e congruente com a tradição ("sempre foi feito assim"). Se o problema for doença transmitida por vetor, a "solução" é a eliminação deste. Se o vetor apresentar resistência, aumenta-se a dose do pesticida, e assim por diante.

Contudo, como o esteio da tradição é sempre "o que foi", falta-lhe variedade de alternativas para dar conta de um mundo sempre incerto e em permanente transformação. Ainda que as relações sociais possam ser subjugadas pelo controle da vontade, a natureza não se sujeita às idéias, como bem demostram as catástrofes. Em outras palavras, é no confronto empírico que o saber tradicional não consegue conter as suas contradições e que o pragmatismo se revela como força conservadora. Se nada mudar, tudo poderá ser feito como sempre foi e o custo será mínimo para todos, ainda que, ao final, todos pereçam. E assim seguem as promoções de campanhas, a confecção de cartazes e peças publicitárias, quer no controle das grandes endemias, quer na prevenção do simples acidente de trabalho.

O exercício da relação democrática, portanto, tem um custo a ser pago, e é a minimização deste custo, ou a "otimização" dos processos de relação, que promove os meios justificados nestes fins minimalistas. Com esse referencial no "fazer", a "solução democrática" do problema de saúde ambiental passa a ser a "conscientização", onde a possibilidade do diferente é recalcada pelo discurso de convencimento. Este discurso, quer seja vulgar ou perito, quando há apelo à autoridade técnica, ignora que a sua forma está em contradição com o seu propósito, uma vez que se espera que os sujeitos abram mão da otimização (que lhes maximiza a relação de troca econômica) em prol de um "interesse coletivo" (o ambiente). Tal apelo socialista ao "bem comum" cai no vazio, pois a consciência, enquanto conhecimento de relações a partir dos fatos, mostra que, nas relações de mercado, nem o "interesse coletivo" está atento às diferenças circunstanciais dos sujeitos nem o "bem comum" é apropriado de forma eqüitativa.

Um sistema construído com base na acumulação, fruto de trocas assimétricas, não pode se sustentar sem o altruísmo. Por outro lado, como o processo de convencimento pela "conscientização" é inevitavelmente pouco eficaz, a alternativa no campo da ação que se quer político toma outros rumos. $\mathrm{O}$ núcleo do discurso político da atual proposta de "Promoção de Saúde", por exemplo, é a necessidade de "capacitação de comuni- 
dades", de forma que as ações possam contar com a sua "participação no controle do processo" (Carta de Otawa, 1986) ${ }^{6}$. Reconhece-se que a solução para melhoria está na "mobilização de recursos e criatividade de indivíduos e comunidade" (Declaração de Sundsvall, 1991) ${ }^{6}$, capaz de "levar em conta as tradições culturais e processos sociais que forjaram nossas nacionalidades" (Declaração de Bogotá, 1992) ${ }^{6}$. A questão é: Trata-se agora de uma forma de ação política no âmbito das garantias da liberdade? A participação e a consideração da validade de uso dos recursos e da criatividade individual, bem como das tradições e dos processos históricos individuais traduzem expressão da liberdade?

A rigor, a resposta a estas questões seria sim. Contudo, quando as proposições são justificadas nas mesmas declarações pela necessidade de "mudanças drásticas nas atitudes e comportamentos" (Declaração de Sundsvall, 1991) ${ }^{6}$, ou pelas "mudanças no estilo de vida das comunidades" (Declaração de Bogotá, 1992) ${ }^{6}$, impulsionada pela "mudança de valores" (ibid.), pode-se colocar em dúvida a garantia de espaço para a expressão da subjetividade. Nas condições colocadas, a ação, enquanto auto-ação ou ação participativa, deve se dar pela mobilização e iniciativa dos sujeitos e das suas convicções, desde que o resultado seja a mudança delas mesmas. Ou seja, devo mudar aquilo em que acredito na minha forma de ser, por razões da minha própria crença ou forma de ser. Aquilo que deveria ser o fim, a preservação da identidade nas diferentes formas, passa a ser o meio para operar algo que é um dado externo ao sujeito, um "dever ser”. O que se configura desta forma é a possibilidade de um convencimento político de que nada melhora porque nada se faz "como se deve". Todavia, é a incerteza, no campo do pensamento, que exclui a validade exclusiva do "como se deve" do campo da ação, abrindo espaço para as possibilidades e suas conseqüências (Figura 2).

Mas a autoridade, pragmática, enquanto tradição e enquanto perita, pode aceitar que a vontade se expresse ponderando os fatores de risco desta forma? Pode esta mesma autoridade conceber que a tão apregoada "qualidade de vida" decorre de um juízo, capaz de valorizar, por exemplo, mais a comunicação do que o saneamento básico? Em suma, pode haver participação ou auto-ação verdadeira sem se compartilhar o pressuposto de que o passado não traduz certezas e que as possibilidades estão no futuro? É muito provável que uma antena parabólica não reduza a mortalidade por doenças entéricas, mas é também bem possível que as relações com o mundo não sejam mais as mesmas depois dela. Quem pode dar certeza?

\section{Conclusões}

A incerteza é a interface entre o campo de pensamento e o campo da ação. Se sua ausência é a paz e o conformismo, sua presença é a pura aflição, como também a razão da esperança. Enquanto o campo do pensamento configura a concepção de risco, o campo da ação é onde o risco se expressa. À medida que o primeiro circunscreve a sua gestação, o segundo potencializa o seu produto. Processo e produto se encontram, se extinguem ou irrompem no absolutamente novo, naquilo que o desejo jamais havia sonhado. Negar as possibilidade do futuro, reduzindo-o às certezas do passado, é negar as possibilidades dos sonhose, portanto, é reduzir a condição humana.

Se o ato "não natural" do velejar traduz a humanidade do homem, enquanto ruptura violenta da ordem cíclica do mundo natural, o "velejar" traduz também o contexto de risco.É, em síntese, a condição humana inscrita entre os "riscos artificiais" e os "riscos naturais" como foi proposto ${ }^{1}$. A violência do velejar configura a possibilidade do naufrágio (o "risco artificial") na aflição da fome diante do lago piscoso (o "risco natural"). Todavia, não é o ato de velejar em si que humaniza o homem neste contexto, como se essa ação pudesse dar sentido ou fim à sua existência, mas é a sua opção pelas outras formas de sustento desconhecidas ou inusitadas, como o velejar, que o distingue. Em outras palavras, não é uma dada condi- 
ção de risco, imposta ou negada, que pode assegurar a dignidade humana, mas sim o exercício da liberdade, liberdade para agir desta ou daquela forma. Mas a liberdade só pode ser exercida por homens livres, e os homens são livres quando detém liberdades instrumentais básicas, que o capacitam à vida econômica e social, como quis Amartya $\operatorname{Sen}^{15}$. É por isso que a promoção humana só pode ser alcançada tendo a liberdade ao mesmo tempo como meio e fim, aquilo que Sen ${ }^{15}$ propõe enquanto "desenvolvimento como liberdade". Na condição da miséria, não há liberdades porque também não há opções. É nela que viceja o discurso da tradição opressora ou da perícia "comprometida”. São as diferentes formas de autoridade que esperam tudo resolver pela "conscientização", como se o viver da própria miséria na degradação ambiental e humana não fosse condição suficiente à consciência da iniqüidade que se vive.

O pressuposto de círculo virtuoso para a economia (enquanto produção de riqueza) contrapõe-se ao círculo vicioso para a natureza (inclusive aquela dos homens). Não há como escapar da contradição, estabelecida como verso e reverso da ação. Todavia, existe ainda um outro círculo virtuoso: aquele promovido pela incerteza, que o conceito de risco tenta configurar. Nele, não há otimizações racionais, não há também promoção do ideal econômico ou do ideal "natural”, harmônico e equilibrado. Dele não emerge resultados excepcionais. O círculo virtuoso da dúvida proporciona apenas a emergência do insólito, ou daquilo ainda não imaginado, possibilidade exclusiva do sujeito que pensa, sente e age.

A consecução do pleno objetivo de mudar a partir do próprio sujeito, como vem sendo proposto ${ }^{6}$, só faz sentido sob a plena garantia da liberdade, não apenas naqueles aspectos instrumentais, mas também da liberdade para seguir, desviar, acertar, errar, sofrer e possivelmente vencer. O que deve importar não pode ser o resultado em si, como almejado na ação pragmática justificada nos fins. O que sempre importa é o processo, capaz de promover cada vez mais a liberdade, através das descobertas sobre possibilidades inusitadas, sobre a natureza, sobre os homens e, principalmente, sobre cada indivíduo sobre si mesmo.

\section{Referências}

1. Lieber RR, Romano-Lieber NS. O conceito de risco: Janus reinventado. In: Minayo MCS, Miranda AC. Saúde e ambiente sustentável: estreitando os nós. Rio de Janeiro: Ed. Fiocruz/Abrasco; 2002. p. 69-111.

2. Arendt H. Entre o passado e o futuro. 5 ed. São Paulo: Ed. Perspectiva; 2001.

3. Ordonez GA. Salud ambiental: Conceptos y actividades. Rev Panam Salud Publica/Pan Am J Public Health 2000; 7(3):137-47.

4. Tambellini AT, Câmara VM. A temática da saúde e ambiente no processo de desenvolvimento do campo da saúde coletiva: Aspectos históricos, conceituais e metodológicos. Ciência \& Saúde Coletiva 1998; 3(2):4759.

5. Luhmann N. Risk: A sociological theory. New York: Aldine de Gruyter; 1993.

6. Brasil (Ministério da Saúde/Fundação Oswaldo Cruz/ IEC) Promoção da saúde. Brasília, DF: Ministério da Saúde; 1996.
7. Kerney R, Rainwater M (eds.). The continental philosophy reader. London: Routledge; 1996.

8. Kuhn TS. A estrutura das revoluções científicas. São Paulo: Ed. Perspectiva; 1975.

9. Pareto V. Noção geral de equilíbrio econômico. In: Pareto V. Manual de economia política. São Paulo: Ed. Nova Cultural; 1996. p. 123-97.

10. Motta SLS, Rossi F. A influência do fator ecológico na decisão de compras de bens de conveniência. Rev Administração Mackenzie 2001; 2(1):109-130.

11. Young HP. Preservação ambiental: Uma retórica no espaço ideológico da manutenção do capital. Rev FAE (Curitiba) 2001; 4(3):15-24.

12. Schumpeter JA. Teoria do Desenvolvimento Econômico - Uma investigação sobre lucros, capital, crédito, juro e o ciclo econômico. São Paulo: Ed. Nova Cultural; 1997. 
13. Lieber RR, Romano-Lieber NS. Acidentes e catástrofes: Causa ou fatores de risco? In: Anais do $21^{\circ}$ Encontro Nacional de Engenharia de Produção (ENEGEP), Salvador, BA. Associação Brasileira de Engenharia de Produção, ABEPRO,UFRGS, Porto Alegre-RS, 2001. (cdrom).
14. Adorno TW. Minima Moralia. Reflexões a partir da vida danificada. São Paulo: Ed. Ática; 1992.

15. Sen A. Desenvolvimento como liberdade. São Paulo: Cia. das Letras; 2001.

Recebido em: 24/07/2002

Aprovação em: 29/10/2002 